\title{
SYNTHESIS, STRUCTURE, THERMAL STABILITY AND FLUORESCENCE OF A NEW CADMIUM(II) COORDINATION POLYERS AS PRECURSOR FOR PREPARATION OF CdO MICRO-CRYSTAL
}

\author{
GANG WU ${ }^{\text {a }}$ ZHI-CHAO LI ${ }^{\text {a }} X I A O-F E N G W A N G^{* b}$ \\ ${ }^{\mathrm{a}}$ College of Material and Chemical Engineering, Chu Zhou University, 239012, China \\ ${ }^{\mathrm{b}}$ College of Environmental Science, Nanjing Xiaozhuang University, 211171, Nanjing, China
}

\begin{abstract}
A new complex $\left[\mathrm{Cd}(\mathrm{btca})_{05}\left(\mathrm{H}_{2} \mathrm{O}\right)_{3}\right](1)\left(\mathrm{H}_{4}\right.$ btca: 1,2,4,5-benzenetetracarboxlyic acid) has been synthesized and characterized by single crystal X-ray diffraction studies, elemental analysis and FT-IR. In compound 1, Cd(II) center atoms coordinate to three ligand btca ${ }^{4}$ anions and three water molecules with a six-coordinated distorted octahedral geometry. Four carboxyl groups of btca ${ }^{4}$ adopt $\mu_{2}-\eta^{2}: \eta^{0}$ and $\mu_{1}-\eta^{1}: \eta^{0}$ two different coordination modes. The whole anion btca ${ }^{4}$ acts as a hexadentate bridge to connect adjacent $\mathrm{Cd}(\mathrm{II})$ atoms, resulting in $2 \mathrm{D}$ layer structure. Further, these two-dimensional layers are linked together by $\mathrm{O}-\mathrm{H} \cdots \mathrm{O}$ to give rise to three-dimensional structure. Thermal stability and luminescent property of 1 are investigated. CdO micro-crystalline particles are then produced by calcination of compound 1 at $580^{\circ} \mathrm{C}$. The obtained $\mathrm{CdO}$ is characterized by XRD and SEM analyses.
\end{abstract}

Keywords: Cd(II) complex; carboxyl group; thermal stability; luminescent property

\section{INTRODUCTION}

Design and construction of metal-organic frameworks (MOFs) formed by joining the metal centers with organic linkers has attracted considerable attention because of their intriguing structural topologies and versatile applications in the areas of photoluminescence, ion exchange, redox catalysis, adsorption, separation, magnetism and sensors ${ }^{[1-6]}$. In these search, Carboxylic acids with aromatic rings owing to rigidity of aromatic rings are widely used in the construction of high-dimensional metal coordination polymers, for example, 1,3,5-benzenetricarboxylic acid, 1,4-naphthalenedicarboxylic acid, and so on, because these anions are able to act as bridging ligands in various ligating modes, resulting in abundant structural motifs ${ }^{[7]}$. 1,2,4,5-benzenetetracarboxylic acid also has been extendedly used to synthesized complexes because of its high symmetry and rigidity ${ }^{[8-10]}$. A great number of carboxylate bridged MOFs have been produced and reported because of the fascinating structures of metalcarboxylate clusters, potential applications, and fantastic topological networks ${ }^{[11-14]}$. On the other hand, cadmium shows few of the characteristic properties of transition metals because it does not have partially filled d orbital, and prefers the $2+$ oxidation state in most of its complexes. More significantly, its spherical $\mathrm{d}^{10}$ configuration makes it particularly suited for the construction of coordination polymers and networks, and also facilitates diverse coordination geometries that allow the formation of multi-form metallo supramolecular materials ${ }^{[15]}$. A series of topological types of one, two, and three-dimensional coordination polymers have been synthesized and reported ${ }^{[16-22]}$.

In addition, The IIB binary compound semiconductors are technologically important materials for optoelectronic applications. Cadmium oxide (CdO) has high optical transmittance and high electrical conductivity properties in the visible region of the solar spectrum, and a moderate refractive index. It is well known that cadmium oxide $(\mathrm{CdO})$ is a semiconductor with direct band gap of $2.2 \mathrm{eV}(520 \mathrm{~nm})$. This material has various applications including solar cells, transparent electrodes, photodiodes, photodiodes and gas sensors, which make this material very suitable for modern technologies ${ }^{[23,24]}$. Therefore, synthesis of nanoparticles or micro-crystal of $\mathrm{CdO}$ has attracted more and more attention in recent years. Many methods have been used and reported in the literature, including sol-gel ${ }^{[25]}$, hydrothermal and solvothermal synthesis ${ }^{[26]}$, microemulsion method [27], microwave-solvothermal synthesis, surfactantligand co-assisting solvothermal ${ }^{[28,29]}$ and so on ${ }^{[30,31]}$. Considerable effort and methods have been dedicated and used to synthesis of nano-scale or microcrystal particles of metals, metal oxides, metal sulfides, and other nanomaterials, such as nano-ceramic materials, however, little attention and effort was focused on using coordination polymers to synthesize nano-particles or micro-crystal particles ${ }^{[32,33]}$. In this paper we report the preparation and crystal structure of the new $\mathrm{Cd}(\mathrm{II})$ coordination polymer, $\left[\mathrm{Cd}(\mathrm{btca})_{05}\left(\mathrm{H}_{2} \mathrm{O}\right)_{3}\right](1)$, and describe a simple synthetic preparation, study of structures and properties of this coordination compound and its use in the preparation of $\mathrm{CdO}$ microcrystalline particles.

\section{EXPERIMENTAL}

Materials and physical measurements: All reagents commercially available were of reagent grade and used without further purification. C, $\mathrm{H}$ elements analyses were carried out on a Perkin-Elmer 240C elemental analyzer. IR spectra were recorded on a Nicolet 6700 FT-IR spectrophotometer by using $\mathrm{KBr}$ pellet in the range of $4000 \sim 400 \mathrm{~cm}^{-1}$. The luminescent spectra for the solid samples were recorded at room temperature on an Aminco Bowman Series 2 spectrophotometer with a xenon arc lamp as the light source. In the measurements of the emission and excitation spectra, the pass width is 5.0 $\mathrm{nm}$. Thermogravimetric analyses (TGA) were carried out with a SDT Q600 instrument under $100.0 \mathrm{~mL} / \mathrm{min}$ flowing nitrogen, and ramp rate of $20.00{ }^{\circ} \mathrm{C}$ / min from 30 to $800^{\circ} \mathrm{C}$. X-ray powder diffraction (XRD) measurements are performed on a Bruker D8 ADVANCE X-ray diffractometer with $\mathrm{Cu}-\mathrm{K \alpha} 1$ monochromatized radiation at $40 \mathrm{kV}$ and $40 \mathrm{~mA}$. The sample is characterized with a scanning electron microscope (SEM) (JEOL JSM 5600LV) with gold coating.

Preparation and analysis of $\left[\mathrm{Cd}(\mathrm{btca})_{0.5}\left(\mathrm{H}_{2} \mathrm{O}\right)_{3}\right]$ (1): The mixture of 1 , 2, 4, 5-benzenetetracarboxylic acid $25.4 \mathrm{mg}(0.1 \mathrm{mmol})$ and $\mathrm{CdCO}_{3} 8.6 \mathrm{mg}$ $(0.05 \mathrm{mmol})$ in $10 \mathrm{~mL}$ distilled water was heated for about $30 \mathrm{~min}$ in boiling water bath. Then $20.0 \mathrm{mg}(0.25 \mathrm{mmol})$ pyrazine was added. The mixture was cooled to room temperature, colorless block crystals were produced $(8.2 \mathrm{mg})$. $\mathrm{C}_{5} \mathrm{H}_{7} \mathrm{CdO}_{7}$ (291.52): Anal. Calcd. for $\mathrm{C}_{5} \mathrm{H}_{7} \mathrm{CdO}_{7}(\%): \mathrm{C}, 20.60 ; \mathrm{H}, 2.42$. Found: C, 20.56; H, 2.44. FT-IR spectrum $\left(\mathrm{cm}^{-1}\right): 3465(\mathrm{bs}), 1610(\mathrm{~s}), 1585(\mathrm{~s}), 1502(\mathrm{~s})$, 1392(s), 1307(m), 1268(m), 1256(m), 1138(m), 1121(m), 876(m), 835(m), $811(\mathrm{~m}), 771(\mathrm{~m}), 588(\mathrm{~m})$. The micro-crystalline powder sample of 1 was synthesized as follows:

The mixture of 1, 2, 4, 5-benzenetetracarboxylic acid $50.8 \mathrm{mg}(0.2 \mathrm{mmol})$ and $\mathrm{CdCO}_{3} 17.2 \mathrm{mg}(0.1 \mathrm{mmol})$ in $15 \mathrm{~mL}$ distilled water was heated for about $12 \mathrm{~h}$ in boiling water bath. Then $40.0 \mathrm{mg}(0.5 \mathrm{mmol})$ pyrazine and $40 \mathrm{~mL}$ $\mathrm{CH}_{3} \mathrm{CH}_{2} \mathrm{OH}$ were added. The mixture was cooled to room temperature, and white powder was produced $(13.4 \mathrm{mg})$. Elements analyses (\%) Found: C, 20.62; H, 2.51. FT-IR spectrum $\left(\mathrm{cm}^{-1}\right): 3400(\mathrm{bs}), 1605(\mathrm{~s}), 1590(\mathrm{~s}), 1508(\mathrm{~s})$, 1395(s), 1312(m), 1262(m), 1260(m), 1143(m), 1115(m), 873(m), 830(m), 808(m), 769(m), 578(m).

X-Ray Crystallography: The crystal data collection for complex $\mathbf{1}$ was carried out on Bruker CCD ApexII diffractometer at room temperature, using graphite-monochromated Mo-K $\alpha$ radiation $(\lambda=0.7107 \AA)$. An empirical absorption correction was made by a multi-scan type. Out of the 1819 total reflections collected in the $2.36 \leq \theta \leq 24.99^{\circ}$ range, 1276 were independent with $R$ int $=0.0189$, of which 1163 were considered to be observed $(I>2 \sigma(I))$ and used in the succeeding refinement. The structure was solved by direct methods and refined by full-matrix least-squares techniques with SHELXL-97 program ${ }^{[34,35]}$. Anisotropic displacement parameters were refined for all non-hydrogen 
atoms. The hydrogen atoms were added in the riding model. The crystal parameters, data collection and refinement results for the compounds are listed in table 1 . The selected bond lengths and bond angles are listed in Table 2.

Table 1: Crystallographic data for complex 1.

\begin{tabular}{|c|c|}
\hline Empirical formula & $\mathrm{C}_{5} \mathrm{H}_{7} \mathrm{CdO}_{7}$ \\
\hline F. w. & 291.52 \\
\hline Crystal system & triclinic \\
\hline Space group & $P-1$ \\
\hline$a(\AA)$ & $5.5924(9)$ \\
\hline$b(\AA)$ & $7.7594(13)$ \\
\hline$c(\AA)$ & $9.6750(16)$ \\
\hline$\alpha(\operatorname{deg})$ & $111.921(2)$ \\
\hline$\beta(\operatorname{deg})$ & $101.810(2)$ \\
\hline$\gamma(\operatorname{deg})$ & $98.277(2)$ \\
\hline$V\left(\AA^{3}\right)$ & $369.84(11)$ \\
\hline Z & 2 \\
\hline Temperature / K & $296(2)$ \\
\hline $\mathrm{D}_{\mathrm{c}}\left(\mathrm{g} \mathrm{cm}^{-3}\right)$ & 2.618 \\
\hline$\mu\left(\mathrm{mm}^{-1}\right)$ & 2.958 \\
\hline Crystal dimension / $\mathrm{mm}$ & $0.32 \times 0.26 \times 0.23$ \\
\hline Crystal color & colorless \\
\hline$\theta$ range $/\left(^{\circ}\right)$ & $2.36-24.99$ \\
\hline Goodness of fit & 1.004 \\
\hline Reflections collected & 1819 \\
\hline Independent reflns & 1276 \\
\hline Obsd. Reflns. $(I>2 \sigma(I))$ & 1163 \\
\hline$F(000)$ & 282 \\
\hline Parameters refined & 118 \\
\hline$R, w R(I>2 \sigma(I))$ & $0.0355,0.1064$ \\
\hline$R, w R$ (all reflections) & $0.0400,0.1083$ \\
\hline
\end{tabular}

Preparation of micro-crystalline cadmium oxide particles: Cadmium oxide micro-crystalline particles were synthesized from powder sample through calcination. The amount of this sample (about $25 \mathrm{mg}$ ) was heated to $580^{\circ} \mathrm{C}$ for $1 \mathrm{~h}$ in air. After cooling, white powder was obtained, which was directly used to study the morphology and size of the sample by means of SEM.

\section{RESULTS AND DISCUSSION}

IR and Crystal Structure of 1: In complex 1, the IR spectra of this complex show broad strong bands at the region $3500-3000 \mathrm{~cm}^{-1}$, which may be related to the existence of $\mathrm{O}-\mathrm{H} \cdots \mathrm{O}$ hydrogen bonding between water molecules. The all carboxyl groups of the $\mathrm{H}_{4}$ btca are completely deprotonated, in good agreement with the IR spectral data since strong band around $1690-1730 \mathrm{~cm}^{-1}$ for $-\mathrm{COOH}$ was not observed ${ }^{[36,37]}$. The IR spectrum of 1 shows characteristic bands of carboxyl groups at $1,585 \mathrm{~cm}^{-1}$ for the asymmetric stretching and at $1,392 \mathrm{~cm}^{-1}$ for symmetric stretching. The volve of $v\left(v_{\mathrm{as}}(-\mathrm{COO}-)-v_{\mathrm{s}}(-\mathrm{COO}-)\right)$ indicate that the carboxylate groups coordinate to the metal atoms bridging $(\Delta \mathrm{v}$ value: $193 \mathrm{~cm}^{-1}$ ) fashion ${ }^{[38]}$. The spectrum also exhibits a strong broad band at $1610 \mathrm{~cm}^{-1}$ indicative of $\mathrm{COO}$ stretching mode, while a peak corresponding to COO vibration appeared at $1392 \mathrm{~cm}^{-1}$ [34-36]. The difference of $v(v$ (-COO)$\left.-v_{\mathrm{s}}(-\mathrm{COO}-)\right)$ is $218 \mathrm{~cm}^{-1}$ characteristic of a unidentate carboxylato group ${ }^{[39,40]}$. All those are consistent with the results of the X-ray analysis.

The X-ray diffraction study for $\mathbf{1}$ reveals that the material crystallizes in the triclinic space group $P-1$. The asymmetric unit contains one $\mathrm{Cd}(\mathrm{II})$ atom, a half of btca ${ }^{4}$ anion and three coordinated water molecules. Selected bond lengths for $\mathbf{1}$ are listed in Table 2. As shown in Figure 1, the Cd1 ion, which is in the center of a distorted octahedral geometry, is surrounded by three carboxylic oxygen atoms from three btca- ligands and three oxygen atoms from three terminal coordinated water molecules. $\mathrm{Cd}-\mathrm{O}$ bond distances are in the range of 2.245(5) - 2.401(5) $\AA$, and the angles of O-Cd-O range from 76.10(19) to 170.87(16) ${ }^{\circ}$. Selected bond lengths and angles are listed in Table 2.

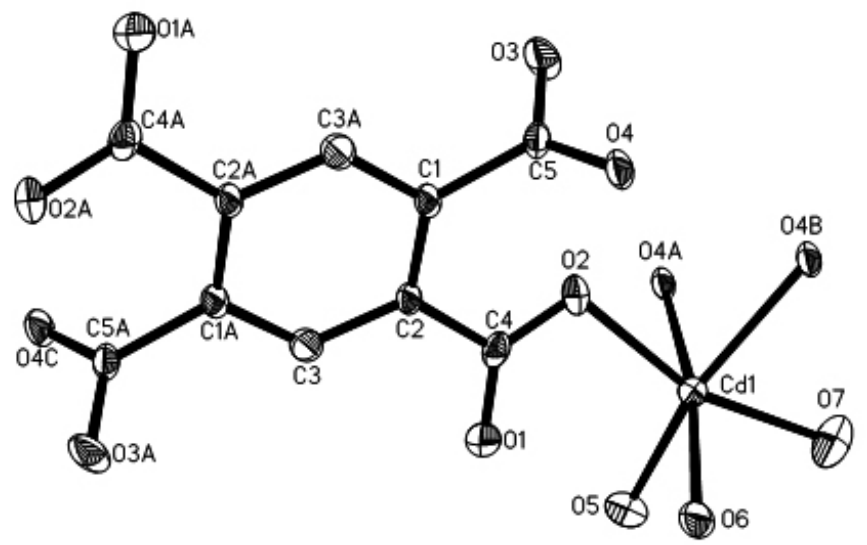

Figure 1: Coordination environment around the Cd(II) atom of 1 with $50 \%$ probability displacement, the hydrogen atoms omitted for clarity; Symmetry code: C1A, C2A, C3A, C4A, C5A, O1A, O2A, O3A, O4C: 2 - x, -y, -z; O4B: $2-\mathrm{x}, 1-\mathrm{y}, 1-\mathrm{z} ;$ O4A: $\mathrm{x}-1, \mathrm{y}, \mathrm{z}$

Table 2: Selected bond lengths $(\AA)$ and angles (deg) for complex 1.

\begin{tabular}{|c|c|c|c|}
\hline Bond & Dist. & Bond & Dist. \\
\hline Cd1-O2 & $2.245(5)$ & Cd1-O5 & $2.280(5)$ \\
\hline Cd1-O4\#1 & $2.312(5)$ & Cd1-O6 & $2.338(5)$ \\
\hline Cd1-O4\#2 & $2.351(4)$ & Cd1-O7 & $2.401(5)$ \\
\hline Angle & $\left(^{\circ}\right)$ & Angle & $\left(^{\circ}\right)$ \\
\hline O2-Cd1-O5 & $114.64(19)$ & O2-Cd1-O4\#1 & $87.48(17)$ \\
\hline O5-Cd1-O4\#1 & $150.44(19)$ & O2-Cd1-O6 & $90.94(18)$ \\
\hline O5-Cd1-O6 & $86.31(19)$ & O4\#2-Cd1-O7 & $85.14(18)$ \\
\hline O4-Cd1-O6\#1 & $113.97(17)$ & O2-Cd1-O4\#2 & $84.80(18)$ \\
\hline O5-Cd1-O4\#2 & $88.12(17)$ & O4\#1-Cd1-O4\#2 & $73.99(17)$ \\
\hline O6-Cd1-O4\#2 & $170.87(16)$ & O2-Cd1-O7 & $162.6(2)$ \\
\hline O5-Cd1-O7 & $79.2(2)$ & O4\#1-Cd1-O7 & $76.10(19)$ \\
\hline O6-Cd1-O7 & $100.9(2)$ & & \\
\hline
\end{tabular}

Symmetry codes: \#1: $2-\mathrm{x}, 1-\mathrm{y}, 1-\mathrm{z} ; \# 2: \mathrm{x}-1, \mathrm{y}, \mathrm{z}$.

In complex 1, the carboxylate groups are not coplanar with centre benzene ring. The angles between benzene ring with carboxylate groups are $78.64^{\circ}(\mathrm{O} 4$ C5-O3, O4C-C5A-O3A), $15.87^{\circ}$ (O1-C4-O2, O1A-C4A-O2A), respectively. In anion $\mathrm{btca}^{4}$, four carboxylate groups take two coordination modes (Figure 2). Two carboxylate groups take $\mu^{1}-\eta^{1}: \eta^{0}$, the other two take $\mu^{2}-\eta^{2}: \eta^{0}$ mode (Figure 2). The whole anion btca ${ }^{4-}$ acts as a hexadentate bridge to connect adjacent $\mathrm{Cd}(\mathrm{II})$ atoms, resulting in 2D layer structure (Figure 2). It is noticeable that there are $\mathrm{Cd}_{2}(\mathrm{COO})_{4}$ clusters in (secondary building block) 1 , which act as four connection nodes, while the btca- anions act as four connection linker, resulting in a two-dimensional grid-like layer with $(4,4)$ topological net(Figure 2).

There are rich $\mathrm{O}-\mathrm{H} \cdots \mathrm{O}$ hydrogen bonds in complex 1 (Table 3). These two-dimensional layers are linked together by $\mathrm{O} 5-\mathrm{H} 5 \mathrm{C} \cdots \mathrm{O} 1, \mathrm{O} 6-\mathrm{H} 6 \mathrm{~B} \cdots \mathrm{O} 1$, O6-H6C $\cdots \mathrm{O} 3$, O6- $\mathrm{H} 6 \mathrm{C} \cdots \mathrm{O} 3$ with a $\mathrm{R}_{1}{ }^{2}(6)^{[41]}$ hydrogen bond pattern to give rise to three-dimensional structure (Figure 3, Table 3 ). 


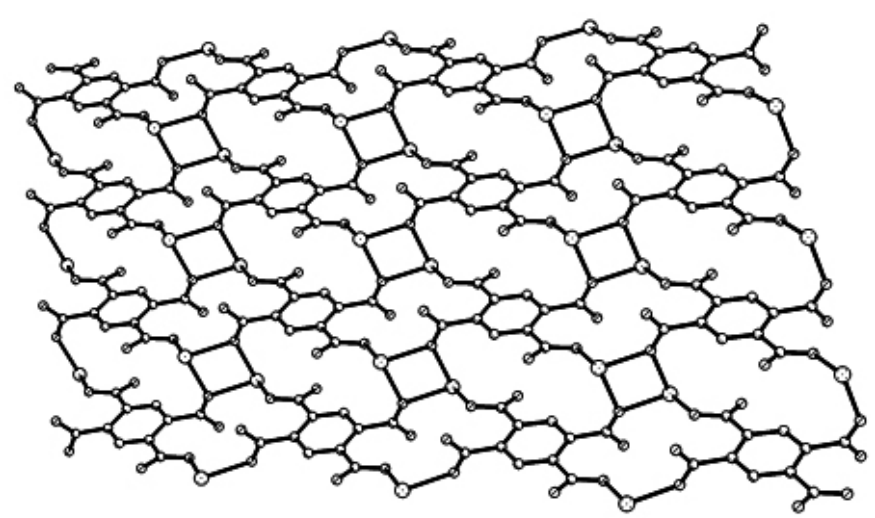

Figure 2: Figure 2 two-dimensional structure of 1, hydrogen atoms and coordinated water molecules omitted for clarity.

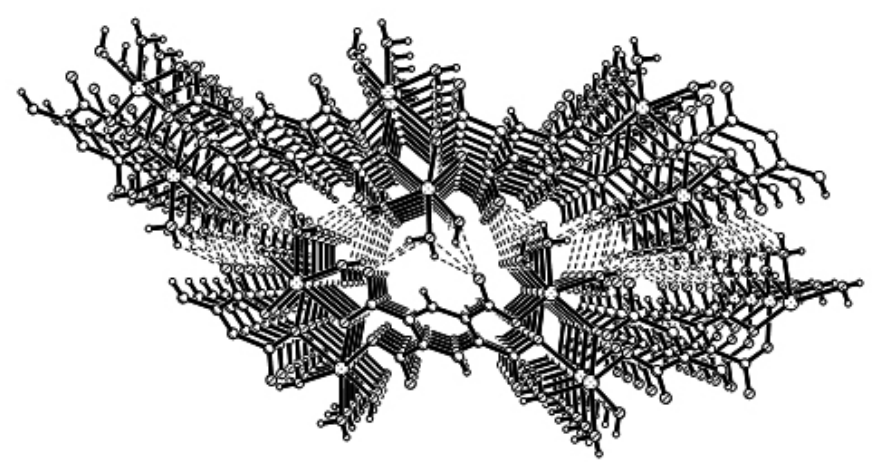

Figure 3: Figure 3 Crystal packing diagram of $\mathbf{1}$, hydrogen bonds indicated by dashed lines.. 1.

Table 3: Distance $(\AA)$ and angles (deg) of hydrogen bonds for the complex

\begin{tabular}{|c|c|c|c|c|}
\hline $\mathrm{D}-\mathrm{H} \cdots \mathrm{A}$ & $\begin{array}{c}d(\mathrm{D}-\mathrm{H}) \\
/ \AA\end{array}$ & $\begin{array}{c}d(\mathrm{H} \cdots \mathrm{A}) \\
/ \AA\end{array}$ & $\begin{array}{c}d(\mathrm{D} \cdots \mathrm{A}) \\
/ \AA\end{array}$ & $\begin{array}{c}\angle(\mathrm{DHA}) \\
/\left({ }^{\circ}\right)\end{array}$ \\
\hline O5-H5B $\cdots \mathrm{O} 6 \# 1$ & 0.81 & 2.32 & $3.015(8)$ & 144 \\
\hline O5-H5C $\cdots \mathrm{O} 1 \# 2$ & 0.81 & 2.16 & $2.778(8)$ & 132 \\
\hline O6-H6B $\cdots \mathrm{O} 1 \# 2$ & 0.85 & 2.12 & $2.803(7)$ & 138 \\
\hline O6-H6C $\cdots \mathrm{O} 3 \# 3$ & 0.85 & 1.98 & $2.743(8)$ & 149 \\
\hline O6-H6C $\cdots \mathrm{O} 3 \# 4$ & 0.85 & 2.52 & $3.051(7)$ & 122 \\
\hline O7-H7A $\cdots$ O2\#5 & 0.85 & 2.33 & $3.058(8)$ & 144 \\
\hline O7-H7A $\cdots$ O3\#5 & 0.85 & 2.27 & $2.814(9)$ & 122 \\
\hline O7-H7B $\cdots$ O3\#4 & 0.85 & 2.47 & $3.215(9)$ & 147 \\
\hline
\end{tabular}

Symmetry transformations are used to generate equivalent atoms: \#1: $-1+$ $x, y, z ; \# 2: 1-x, 1-y,-z ; \# 3: x, 1+y, z ; \# 4: 2-x, 1-y, 1-z ; \# 5: 1-x, 1-y, 1-z$.

Luminescent Property of 1: The solid-state photoluminescent spectrum of complex 1 was measured at room temperature and excited at $250 \mathrm{~nm}$, complex 1 shows one maximum emission spectrum centered at $426 \mathrm{~nm}$ (Figure 4). To ascertain the adscription of emission spectra, the photoluminescence of pure $\mathrm{H}_{4}$ btc was measured under the same conditions. However, the free $\mathrm{H}_{4}$ btc ligand emission peak almost was not observed. The emission band of compound $\mathbf{1}$ may be assigned to $\pi-\pi^{*}$ intraligand fluorescence.

Thermogravimetric Analyses: Complex 1 was subjected to thermogravimetric analysis (TGA) in a $\mathrm{N}_{2}$ atmosphere to ascertain their thermal stability, and he TGA curve of $\mathbf{1}$ was recorded from room temperature to $800{ }^{\circ} \mathrm{C}$ (Figure 5). In the TGA curve of complex $\mathbf{1}$ there is a weight loss of $18.99 \%$ within the temperature range of $117-142{ }^{\circ} \mathrm{C}$, corresponding to the release of three coordinated water molecules (calcd $18.54 \%$ ), and a continuous weight loss (calcd $43.59 \%$ ) starting at $410{ }^{\circ} \mathrm{C}$. In this process, weight loss between 410 to $506{ }^{\circ} \mathrm{C}$ of ca. $45.34 \%$ (calcd. $43.59 \%$ ), corresponding to the loss of a half benzene molecule and two carbon dioxide per formula unit, from the decomposition of btca ${ }^{4-}$, accompanied by the subsequent decomposition of the framework. The final residues may be CdO.

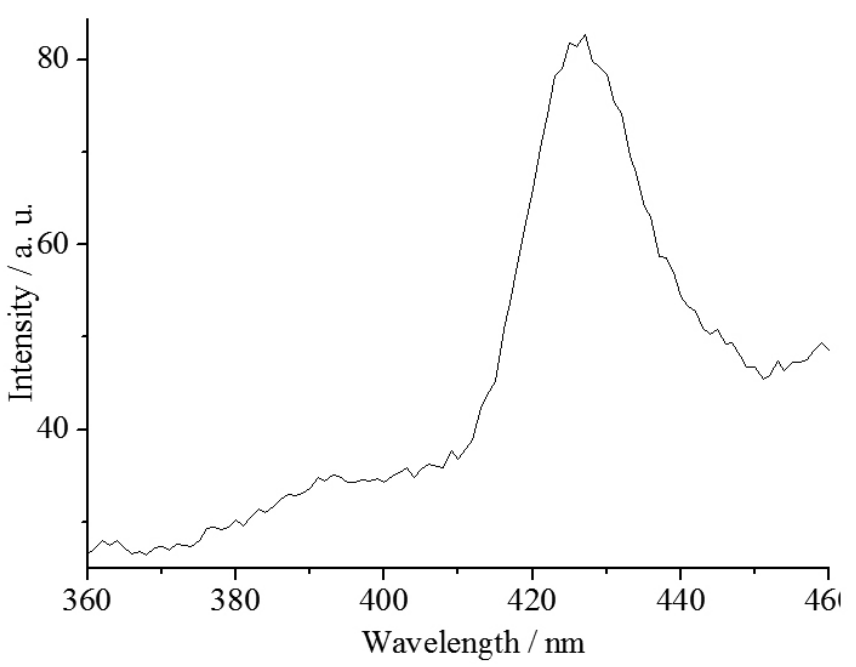

Figure 4: Emission spectrum of complex 1 in solid state at room temperature.

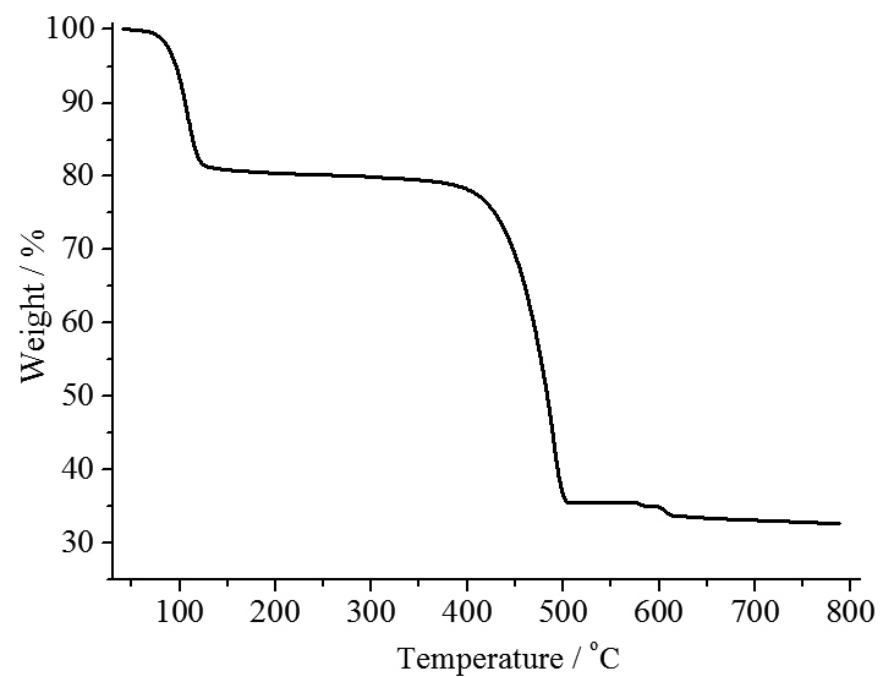

Figure 5: TG curve of 1 .

Figure 6 shows the XRPD pattern calculated from the single crystal data of $\mathbf{1}$ in compared to the XRPD pattern of the typical belt sample of $\mathbf{1}$ prepared by a solvothermal process (Figure 7). Acceptable matches, with slight differences in $2 \theta$ and differences in intensity, are observed. This suggests that the compound obtained has a single crystalline phase and that structure of this phase is identical to that obtained by single crystal diffraction. Figure 7 is the SEM of the micro-crystalline belt produced from solvothermal process. The SEM (Figure 7) indicates that average length, widen and thickness of belts are $1.37,0.38,0.07 \mu \mathrm{m}$, respectively.

CdO micro-crystalline particles were synthesized from the decomposition of the precursor 1 at $580{ }^{\circ} \mathrm{C}$ under air atmosphere. The phase purity of the as-prepared organge yellow orthorhombic $\mathrm{CdO}$ microparticles are completely obvious and all diffraction peaks are perfectly indexed to the cubic $\mathrm{CdO}$ structure with the lattice parameters of $a=4.695 \AA, b=4.695 \AA, c=4.695$ $\AA, Z=4$ and S.G $=F \mathrm{~m} 3 \mathrm{~m}$ which are in JCPDS card file no. 05-0640. No 
characteristic peaks of impurities are detected in the XRD pattern (Figure 8).

Figure 9 is the SEM of as prepared CdO. Compared with Figure 7, we found that the shape of $\mathrm{CdO}$ particles is not same as that of its precursor. But the shape is still belt. The SEM (Figure 9) indicates that average length, widen and thickness of $\mathrm{CdO}$ belts are $1.19,0.31,0.065 \mu \mathrm{m}$, respectively.

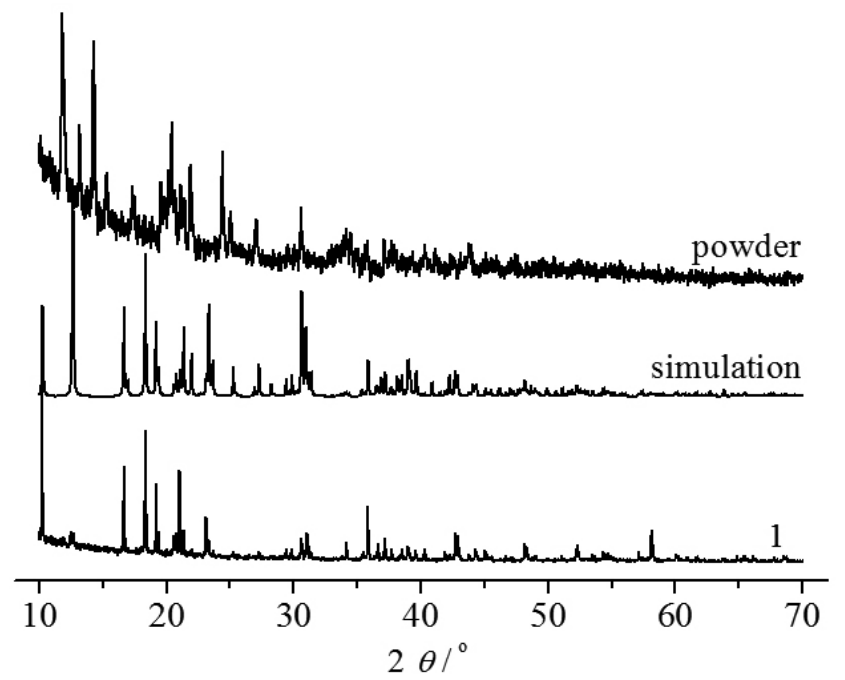

Figure 6: The XRD patterns of a simulated from single crystal X-ray data of complex, $\mathbf{1}$ and the powder sample.

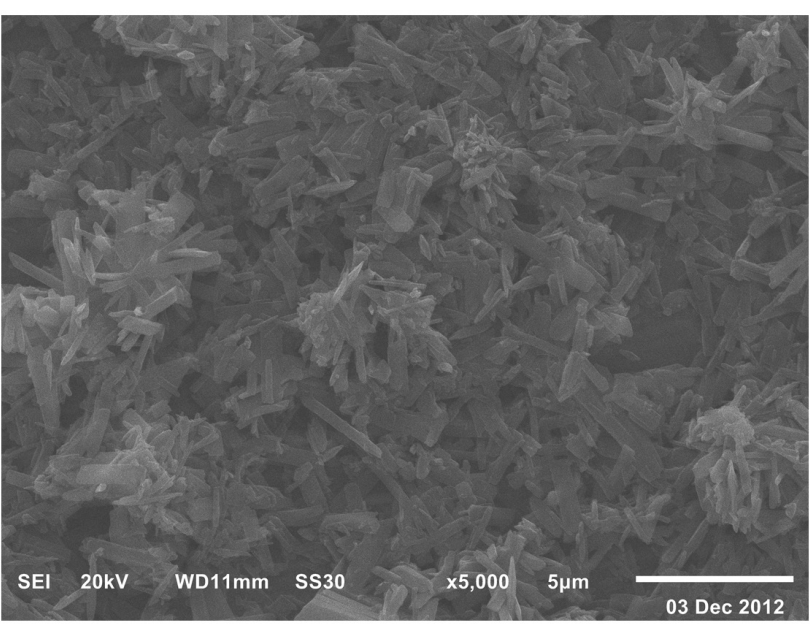

Figure 7: The SEM photographs of micro-crystalline sample.

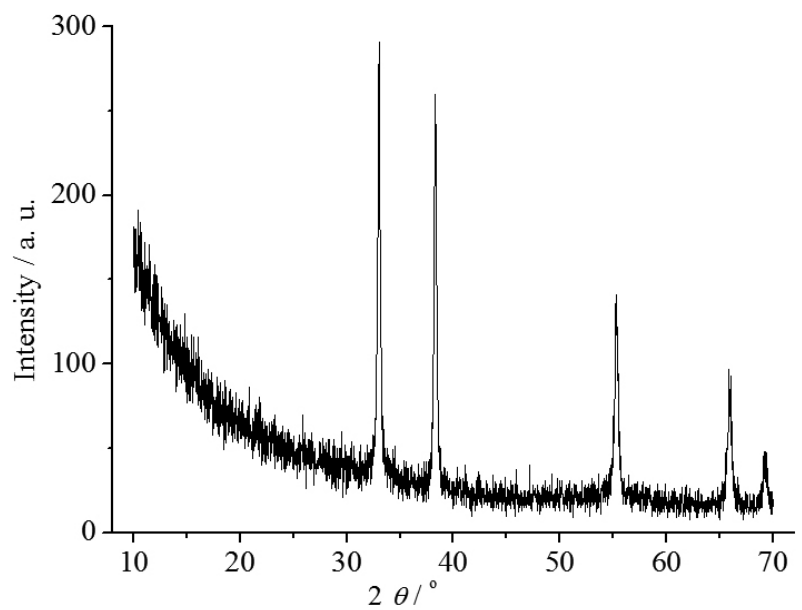

Figure 8: XRD pattern of $\mathrm{CdO}$ prepared from thermolysis of powder sample.

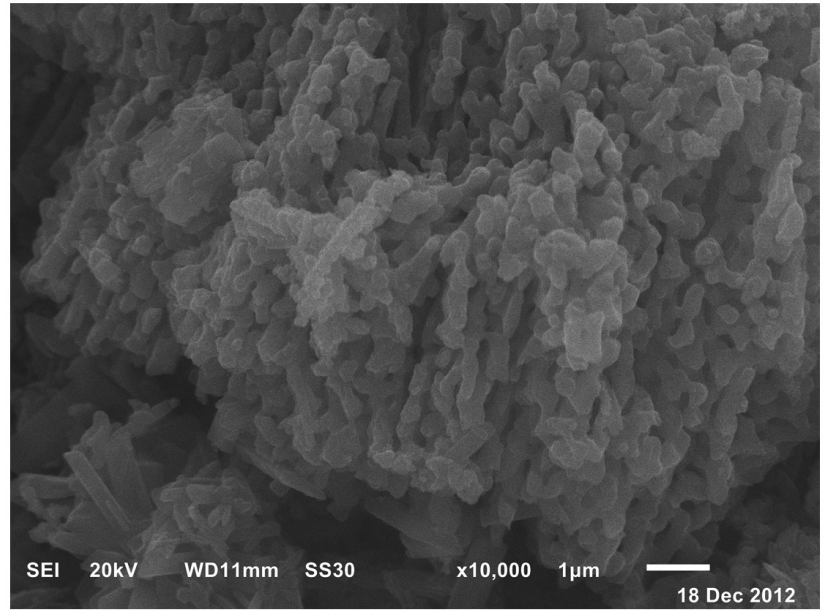

Figure 9: SEM photograph of as-prepared $\mathrm{CdO}$ produced by calcinating precursor at $580^{\circ} \mathrm{C}$.

\section{CONCLUSIONS}

In summary, the syntheses, crystal structures, thermal stability and luminescent properties of a new $\mathrm{Cd}(\mathrm{II})$ polymer have been described. Compound feature a 2D network. The btca ${ }^{4}$ anions act as four connection linker connect $\mathrm{Cd}_{2}(\mathrm{COO})_{4}$ clusters, which adopt four connection nodes, resulting in a two-dimensional grid-like layer with $(4,4)$ topological net. Thermal stability of three complexes and luminescent property of $\mathbf{1}$ are investigated. The $\mathrm{CdO}$ belt micro-crystalline particles were obtained by thermolysis of powder sample at $580^{\circ} \mathrm{C}$. The scanning electron microscopy shows that the thickness of the $\mathrm{CdO}$ and its precursor particles is $\sim 0.07 \mu \mathrm{m}$.

\section{Supplementary material}

Crystallographic data for the compound have been deposited with the Cambridge Crystallographic Data Centre, CCDC reference numbers 913621 for 1. This information may be obtained free of charge from: the Director, CCDC, 12 Union Road, Cambridge, CB2 1EZ, UK (fax: +44-1223-336033; e-mail: deposit@ccdc.cam.ac.uk; website: http://www.ccdc.cam.ac.uk).

\section{ACKNOWLEDGMENTS}

The authors are grateful to grateful to An Hui Province Natural Science Foundation (1208085MB31) and Student Creative Project of Chuzhou University for financial support of this work.

\section{REFERENCES}

1. M.D. Allendorf, C.A. Bauer, R.K. Bhakta, R.J.T. Houk, Chem. Soc. Rev. $38,1330,(2009)$.

2. C.N.R. Rao, S. Natarajan, R. Vaidhyanathan, Angew. Chem. Int. Ed. 43, 1466, (2004).

3. D. Bradshaw, J.B. Claridge, E.J. Cussen, T.J. Prior, M.J. Rosseinsky, Acc. Chem. Res. 38, 273, (2005).

4. A.Y. Robin, K.M. Fromm, Coord. Chem. Rev. 250, 2127, (2006).

5. K. Liang, H.G. Zheng, Y.L. Song, M.E. Lappert, Y.Z. Li, X.Q. Xin, Z.X. Huang, J.T. Chen, S.F. Lu, Angew. Chem. Int. Ed. 43, 5776, (2004).

6. Y. Liu, W.M. Xuan, Y. Cui, Adv. Mater. 22, 4112, (2010).

7. J. Yang, Q. Yue, G.D. Li, J.J. Cao, G.H. Li, J.S. Chen, Inorg. Chem. 45, 2857, (2006).

8. J.C. Yao, L.L. Wu, Y.G. Li, X.L. Mei, J. Chem. Crystallogr. 39, 246, (2009).

9. G. Li, G. Wu, H.H. Li, J. Chem. Crystallogr. 42, 192, (2012).

10. Y. Ding, H.L. Chen, E.B. Wang, X.X. Xu, X.L. Wang, C. Qin, Transition Met. Chem. 33, 183, (2008).

11. J.L.C. Rowsell, A.R. Millward, K.S. Park, O. M. Yaghi, J. Am. Chem. Soc. $126,5666,(2004)$.

12. J.L.C. Rowsell, O.M. Yaghi, J. Am. Chem. Soc. 128, 1304, (2006).

13. Q.B. Bo, Z.X. Sun, G.L. Song, G.X. Sun, J. Inorg. Organmet. Polym. 
Mater. 17, 615, (2007).

14. L.Y. Zhang, G.F. Liu, S.L. Zheng, B.H. Ye, X.M. Zhang, X.M. Chen, Eur. J. Inorg. Chem. 2965, (2003).

15. Y. Dai, E. Ma, E. Tang, J. Zhang, Z. Li, X. Huang, Y. Yao, Cryst. Growth Des. $5,1313,(2005)$.

16. K.M. Blake, G.A. Farnum, L.L. Johnston, R.L. LaDuca, Inorg.Chim. Acta, $363,88,(2010)$

17. A. Morsali, M. Payheghader, M.R. Poorheravi, F. Jamali, Z. Anorg, Allg. Chem. 629, 1627, (2003).

18. J. Ding, X. Liu, B. Li, L. Wang, Y. Zhang, Inorg. Chem. Commun. 11, 1079, (2008)

19. D.M. Ciurtin, Y.B. Dong, M.D. Smith, T. Barclay, H.C. zur Loye, Inorg. Chem. 40, 2825, (2001).

20. E. Shyu, M.A. Braverman, R.M. Supkowski, R.L. LaDuca, Inorg. Chim. Acta 362, 2283, (2009)

21. M.A. Braverman, R.M. Supkowski, R.L. LaDuca, J. Solid State Chem. 180, 1852, (2007).

22. Y. Ma, Y.K. He, L.T. Zhang, X.F. Wang, J.Q. Gao, Z.B. Han, Struct. Chem. 18, 1005, (2007).

23. R. Kaur, A.V.J. Singh, Non-Cryst. Solids 2335, (2006).

24. W. Dong, C. Zhu, Opt. Mater. 22, 227, (2003).

25. A. Askarinejad, A. Morsali, Mater. Lett. 62, 478, (2008).

26. S. Ashoka, P. Chithaiah, G.T. Chandrappa, Mater. Lett. 64, 173, (2010).

27. G. Nagaraju, S. Ashoka, C.N. Tharamani, G.T. Chandrappa, Mater. Lett. $63,492,(2009)$.
28. C. Li, X. Yang, B. Yang, Y. Yan, Y.T. Qian, J. Cryst. Growth 291, 45, (2006).

29. J. Yang, J.H. Zeng, S.H. Yu, L. Yang, G.E. Zhou, Y.T. Qian, Chem. Mater. 12, 3259, (2000).

30. T. Mandal, V. Stavila, I. Rusakova, S. Ghosh, K.H. Whitmire, Chem. Mater. 21, 5617, (2009).

31. Z. Popovic, G. Pavlovic, M. Vinkovic, D. Vikic-Topic, M.R. Linaric, Polyhedron 25, 2353, (2006)

32. S. Khanjani, A. Morsali, J. Mol. Struct. 935, 27, (2009).

33. A. Aslani, A. Morsali, Inorg. Chim. Acta 362, 5012, (2009).

34. G.M. Sheldrick, SHELXS 97, Program for the Solution of Crystal Structure, University of Göttingen, Germany (1997).

35. G.M. Sheldrick, SHELXL 97, Program for the Refinement of Crystal Structure, University of Göttingen, Germany (1997).

36. Q. Shi, R. Cao, D.F. Sun, M.C. Hong, Y.C. Liang, Polyhedron 20, 3287, (2001).

37. Z.B. Han, X.N. Cheng, X.M. Chen, Cryst. Growth Des. 5, 695, (2005).

38. X.L. Wang, C. Qin, E.B. Wang, Y.G. Li, N. Hao, C.W. Hu, L. Xu, Inorg. Chem. 43, 1850, (2004).

39. K. Nakamoto, Raman and Infrared Spectra of Inorganic and Coordination Compounds, 4th ed. Wiley, New York, (1986).

40. B.M. Kukovec, Z. Popović, B. Kozlevčar, Z. Jagličič, Polyhedron 27, 3631, (2008).

41. J. Bernstein, R.E. Davis, L. Shimoni, N.-L. Chang, Angew. Chem. Int. Ed. Engl. 34, 1555, (1995). 